\title{
Egg donation and surrogate motherhood: opposed ideologies, common goal
}

Keywords: egg donation, surrogate motherhood, reproductive tourism, ethical debate, legislation, Spain

\section{Opinion}

Egg donation and surrogate motherhood represent two entirely different, yet equally controversial approaches to the treatment of infertility. The legal regulation of the use of these methods varies from country to country, which is at the origin of what is commonly called "fertility or reproductive tourism". Egg donation is legal in most countries, but it is subject to specific requirements and administrative regulations which make its availability unequal in different places of the world. Surrogate motherhood, on the other hand, is legally accepted only in a few countries and, similar to egg donation, it is conditioned by different restrictive measures in each of them (Table 1). Among the countries that allow egg donation, distinction has to be made between those accepting this treatment unconditionally and those that impose specific restrictions to its practice. The most common restriction concerns the economic compensation of the donor (Table 1). On the one hand, altruistic egg donation (no economic compensation) helps limit abusive commercialization of the human body. On the one hand, it reduces the availability of donor eggs in the home country and thus promotes fertility tourism with all its potential problems related to the elevated cost of the procedure in some places and the insufficient sanitary and legal regulation in others. Other restrictions of egg donation encountered in some countries concern the marital status, sexual orientation, permanent residency in the country, or religion of the couple receiving donated oocytes. Some countries impose bilateral anonymity for the egg donation transaction.

Surrogate motherhood is allowed unconditionally (both altruistic and commercial one) in only a few countries, and only some of these provide corresponding legal coverage (Table 1). The countries with most complete legal coverage to both altruistic and commercial surrogate motherhood include Armenia, Belarus, Greece, Israel, Kazakhstan, Russia, Ukraine and some states of the USA (California, Connecticut, Nevada, New Hampshire, Oregon, Maine, Rhode Island). In other countries both altruistic and commercial surrogacy is possible, but there are specific restrictions or legal gaps that complicate the administrative recognition of the social couple (intended parents) as the legal parents of the resulting child. The most common restrictions include sharing the same religion by the intended parents and surrogate (Israel) having the citizenship or permanent residence in the country (Israel, Mexico, Thailand) and the marital status of the couple. As a matter of example, unmarried heterosexual couples (Arkansas) and homosexual couples (India) can be banned from surrogacy. Unconditional surrogacy with complete legal coverage is provided only in relatively few places of the world (e.g., California, Greece, Ukraine). The unequal access to egg donation and surrogate motherhood in different countries is at the origin of reproductive tourism with all its negative consequences (elevated cost, insufficient sanitary and legal guarantees, exploitation of economically weak subjects). This situation can only be alleviated by approaching the
Volume 4 Issue $3-2017$

\author{
Jan Tesarik \\ MARGen Clinic, Spain
}

Correspondence: Jan Tesarik, MARGen MARGen Clinic, Camino de Ronda 2, 18006 Granada, Spain, Tel +34 606376992 Fax+34958818277, Email jtesarik@clinicamargen.com

Received: February 19, 2017| Published: February 22, 2017

conditions required for these treatments in different parts of the world. In accordance with this idea, some countries have engaged debate at different levels to release the existing restrictions. The debate about eventual legalization of surrogate motherhood has recently burst with force in Spain.

Interestingly, the partisans and opponents of this treatment do not appear to have any definite political color. Notwithstanding, as almost all aspects of the current social life, opinions about surrogacy are conditioned by non political ideologies, if we defined the ideology as a set of conscious and unconscious ideas which make up one's beliefs, goals, expectations and motivations. Many of my colleagues, who always been strongly in favor of egg donation, refuse surrogate motherhood for ideological reasons, simply because the ideology backing surrogacy is entirely opposed to that they have been using to defend egg donation. Women seeking for egg donation are said that the experience of pregnancy and birth are at the basis of future conscious and unconscious emotional links between the mother and the future child, whereas the biological (genetic) motherhood is something related to learned knowledge rather than direct life experience. This argument is generally well received, and usually makes the acceptance of egg donation by female patients more easy than the acceptance of sperm donation by male patients in a similar condition. However, this reasoning has to be completely inverted when talking about surrogate motherhood, where the female patient will only share the genetic makeup with the future child, without any prenatal physical contact. If surrogacy is combined with egg, sperm or embryo donation, even the genetic parent-child lineage is lost. How to manage the need for using such different patterns of thinking when dealing with different categories of patients? New challenges call for new thinking patterns, and one possibility is to transcend traditional ideologies and abandon pseudo scientific rationales, based on the kantian dyad, in a hegelian way. In this way, the apparent ideological incompatibility of the thesis (parenthood through egg donation) and its antithesis (parenthood through surrogacy) would be transcended by forming a triad in which the legitimate desire for parenthood would represent a synthesis in which the apparently incompatible concepts can be englobed in the same ideology-free vision. It remains to be seen to what extent we are able to do so. 
Table I Availability of oocyte donation and surrogate motherhood in some countries

\begin{tabular}{|c|c|c|}
\hline Country & Egg donation & Surrogate motherhood \\
\hline Argentina & Altruistic egg donation allowed & Altruistic surrogacy allowed \\
\hline Armenia & Egg donation allowed & Surrogacy allowed and regulated \\
\hline Australia & Altruistic egg donation allowed & Altruistic surrogacy allowed \\
\hline Austria & Egg donation allowed & All surrogacy illegal \\
\hline Belgium & Egg donation allowed & Altruistic surrogacy allowed \\
\hline Belarus & Egg donation allowed & Surrogacy allowed and regulated \\
\hline Brazil & Altruistic egg donation allowed & Altruistic surrogacy allowed \\
\hline Canada & Altruistic egg donation allowed & Altruistic surrogacy alowed ${ }^{1}$ \\
\hline China & Egg donation illegal & All surrogacy illegal \\
\hline Colombia & Egg donation allowed & No clear rules \\
\hline Czech Republic & Egg donation allowed & No legislation \\
\hline Cyprus & Egg donation allowed & Surrogacy allowed \\
\hline Denmark & Altruistic egg donation allowed & Altruistic surrogacy allowed \\
\hline Finland & Egg donation allowed & All surrogacy illegal \\
\hline France & Altruistic egg donation allowed & All surrogacy illegal \\
\hline Germany & Egg donation illegal & All surrogacy illegal \\
\hline Georgia & Egg donation allowed & Surrogacy allowed \\
\hline Greece & Egg donation allowed & Surrogacy allowed and regulated \\
\hline Hong Kong & Egg donation allowed & Altruistic surrogacy allowed \\
\hline Hungary & Egg donation allowed & Altruistic surrogacy allowed \\
\hline Iceland & Egg donation allowed & All surrogacy illegal \\
\hline India & Egg donation allowed & Surrogacy allowed ${ }^{2}$ \\
\hline Ireland & Egg donation allowed & No legislation \\
\hline Israel & Egg donation allowed with restrictions & Surrogacy allowed and regulated \\
\hline Iran & Egg donation allowed with restrictions & Surrogacy allowed \\
\hline Kazakhstan & Egg donation allowed & Surrogacy allowed and regulated \\
\hline Italy & Egg donation allowed & All surrogacy illegal \\
\hline Japan & Egg donation allowed with restructions & All surrogacy illegal \\
\hline Mexico & Egg donation allowed & Surrogacy allowed to residents \\
\hline Netherlands & Egg donation allowed & Altruistic surrogacy allowed \\
\hline New Zealand & Altruistic egg donation allowes & Altruistic surrogacy alowed \\
\hline Norway & Egg donation illegal & All surrogacy illegal \\
\hline Pakistan & No legislation & All surrogacy illegal \\
\hline Panama & Egg donation allowed & No legislation \\
\hline Portugal & Egg donation allowed & Altruistic surrogacy allowed \\
\hline Russia & Egg donation allowed & Surrogacy allowed \\
\hline Saudi Arabia & Egg donation illegal & All surrogacy illegal \\
\hline Serbia & Egg donation allowed & All surrogacy illegal \\
\hline South Africa & Egg donation allowed & Surrogacy allowed \\
\hline Spain & Egg donation allowed & All surrogacy illegal \\
\hline Sweden & Egg donation allowed & Not clearly regulated \\
\hline
\end{tabular}


Table Continued

\begin{tabular}{lll}
\hline Country & Egg donation & Surrogate motherhood \\
\hline Switzerland & Egg donation illegal & All surrogacy illegal \\
Thailand & Egg donation allowed & Surrogacy allowed for residents \\
Ukraine & Egg donation allowed & Surrogacy allowed \\
United Kingdom & Egg donation allowed & Altruistic surrogacy allowed \\
United States & Egg donation allowed & Varies from state to state \\
Vietnam & Egg donation allowed & Altruistic surrogacy allowed \\
\hline
\end{tabular}

'Except Quebec; ${ }^{2}$ Severe restrictions since 2015.

\section{Acknowledgements}

None.

\section{Conflict of interest}

The author declares no conflict of interest. 